\title{
Produção de videoaula e aprendizagem de matemática: uma opção possível?
}

DOI: $10.23864 /$ cpp-v1-n1-51

\author{
Cosmerina Angélica Soares Cruz Santana
}

Adriana Santos Sousa

\section{Resumo}

Este relato apresenta uma experiência com alunos do Ensino Médio do Colégio Polivalente de Vitória da Conquista - Bahia, na produção de videoaulas sobre Progressão Aritmética e Progressão Geométrica, utilizando uma linguagem que une imagens e sons. Apresenta os estudos de um projeto-pesquisa realizado em parceria com o Núcleo de Tecnologia Educacional (NTE16) e o Grupo de Estudos em Educação Matemática (GEEM) no ano de 2014. O projeto-pesquisa propôs a inserção das tecnologias digitais em sala de aula, em especial o vídeo, e a utilização da produção de videoaulas como estratégia para aprender e ensinar Matemática, com o intuito de aproximar a Matemática do mundo dos estudantes, instigar a pesquisa, a análise, a capacidade de síntese e a elaboração de situações problemas, além de despertar o interesse e a criatividade dos alunos com o uso de uma ferramenta de linguagem multimodal (imagens, falas, música e escrita). As análises iniciais concluem que a maioria dos alunos atingiu os objetivos propostos, pois conseguiu apresentar, em vídeo, de forma clara, organizada e criativa, o que foi aprendido e discutido.

Palavras chave: Produção de Videoaula. Aprendizagem em Matemática. Educação Matemática. Tecnologia Educacional. 


\section{Introdução}

O uso de tecnologias em sala de aula desafia os professores a procurar formas de ensinar e aprender levando em consideração a integralização da dinamicidade da rede de Internet e dos recursos tecnológicos disponíveis com as atividades escolares. Segundo Kenski (2010, p. 18), para despertar o interesse contínuo dos alunos pelas tecnologias, faz-se necessária uma orientação do "[...] caminho de todos para o domínio e apropriação crítica desses novos meios".

Borba e Penteado (2003, p. 64-65), sobre este assunto, sugerem que “[...] à medida que a tecnologia informática se desenvolve, nos deparamos com a necessidade de atualização de nossos conhecimentos sobre o conteúdo ao qual ela está sendo integrada”.

Os Parâmetros Curriculares Nacionais (PCN) (BRASIL, 1999) reforçam esses posicionamentos ao sugerir que o uso das tecnologias contribui para o ensino de Matemática no instante em que desperta nos alunos interesse pela realização de atividades investigativas, cooperativas e criativas. Neste sentido, os espaços disponíveis na rede (blogs, redes sociais, sites de vídeos, slides etc.), embora não tenham sido concebidos originalmente com enfoque educacional, podem incentivar o diálogo, a colaboração e a cooperação pedagógica.

Diante da gama de informações sobre as tecnologias e a possibilidade de aplicá-las em sala de aula, "modernizando-as", os professores, ansiosos por para inserir os recursos tecnológicos em sua prática pedagógica, procuram se aprimorar, aprofundar-se no assunto, participando de cursos de formação continuada, buscando subsídios técnico-metodológicos.

Aliado à escolha das tecnologias mais adequadas às atividades pedagógicas, os docentes estão sempre preocupados em não prejudicar os objetivos educacionais propostos e, principalmente, a aprendizagem dos alunos. Por isso, para incorporar as tecnologias, é importante conduzir os alunos perante as novidades e interatividade, sem perder o foco.

Segundo dados da Pesquisa Nacional por Amostra de Domicílios (PNAD - 2013), entre as tecnologias digitais mais comuns em nossa sociedade está a televisão com a presença em 97,2\% dos lares brasileiros. A popularidade da TV e da linguagem audiovisual permite aliar este recurso com a autoria, incentivando e explorando a criatividade dos alunos e a sua capacidade de compreensão e exposição dos conteúdos matemáticos numa linguagem multimodal (imagens, falas, música e escrita) (DEMO, 2008).

Este relato apresenta uma experiência com 102 alunos do $2^{\circ}$ ano do Ensino Médio do Colégio Polivalente de Vitória da Conquista - Bahia, na produção de videoaulas sobre Progressão Aritmética (PA) ou Geométrica (PG), em que exibem o conteúdo matemático que

${ }^{1}$ Pesquisa completa disponível no link http://www.ibge.gov.br/home/estatistica/populacao/trabalhoerendimento/pnad2013/default.shtm, Acesso em 23/06/2015. 
aprenderam e discutiram em sala de aula de forma criativa numa linguagem que une imagens e sons.

\section{Vídeo como recurso pedagógico}

O uso das tecnologias com enfoque pedagógico representa para os professores uma alternativa para atender às necessidades de alunos cada vez mais conectados e envolvidos com o mundo digital. Os professores, no processo de reflexão e crítica da prática, (re)conhecem e aproveitam esses recursos, incorporando-os em suas aulas.

Segundo Pretto (1996, p.115), a função do docente é articular as informações de modo que "combine a inteligência mental e a inteligência sensível com a imaginação criadora", valorizando os espaços de troca de conhecimentos e construções coletivas em sala de aula. É indispensável, portanto, que o professor estabeleça a união da teoria com a prática na incorporação das tecnologias em sala de aula. Essa combinação o habilita a aliar o seu fazer pedagógico, que agrega valores étnicos, culturais, pedagógicos e metodológicos, com um recurso mais adequado à ação pedagógica (MERCADO, 2008), adquirindo mais liberdade no ensinar e aprender e diversificando as atividades.

Entre as tecnologias digitais disponíveis (Internet, rádio, vídeo, áudio, imagem, site, podcast), o vídeo se destaca, no campo educacional, por apresentar, segundo os alunos, linguagem agradável e envolvente para abordagem dos assuntos. Por isso, segundo Moran (1995, p. 27), os professores utilizam essa "expectativa positiva para atrair o aluno para os assuntos do nosso planejamento pedagógico" atentando para realizar ligações do vídeo com outras dinâmicas pedagógicas.

A linguagem audiovisual associa imagens e sons na apresentação do conteúdo, reverberando ideias, despertando sentidos, criando, recriando e cocriando a realidade. Moran (1995, p. 27) considera que o vídeo é a expressão do concreto, do visível, que toca os sentidos e "pelo vídeo sentimos, experienciamos sensorialmente o outro, o mundo, nós mesmos".

Os vídeos podem ser usados para ilustrar um tema, motivar uma ação e incitar a criatividade dos alunos na construção de novas leituras. Seguindo esta linha, Scucuglia (2012), em pesquisa de doutoramento, estudou a forma com que os alunos de Ensino Fundamental expressam Performances Matemáticas Digitais (DPM), isto é, um texto multimodal / narrativa (vídeo) que estabelece elo entre as artes e as tecnologias na geração de conceitos matemáticos. Scucuglia, entretanto, afirma que, apesar do empenho dos alunos, as produções digitais nem sempre garantiram a conceitualidade matemática dos conteúdos.

Na perspectiva do professor, Sousa (2014, p.44) avalia que experiências como estas permitem ao docente "questionar, problematizar, instigar os estudantes a perceberem a 
relação do que está sendo visto com o conteúdo abordado em sala de aula”. Para Rocato (2009), o uso de vídeos no processo de ensino-aprendizagem, em especial na Matemática, tanto permite interpretações do conteúdo, como possibilita a participação ativa dos alunos na construção, visualização e desmitificação da aprendizagem matemática.

Vale ressaltar que utilizar este recurso em sala de aula, seja como expectador, seja como autor, exige análise minuciosa do que será exibido, dos questionamentos elaborados para antes, durante e após a exibição do vídeo, do tempo e das atividades complementares à ação.

Para Moran (2011, p.39), o processo criativo do vídeo "solicita constantemente a imaginação e reinveste a afetividade com um papel de mediação primordial no mundo”. Neste caminho, deve-se valorizar a autoria considerando a ideia, o roteiro, a montagem das imagens e sons para a abordagem do conteúdo matemático.

\section{Produção de vídeo como estratégia para aprender e ensinar Matemática: um relato de experiência}

Com o intuito de dinamizar as aulas, desde 2009, a professora Cosmerina Angélica vem proporcionando aos alunos vivências no estudo de Matemática que se diferenciam das tradicionais avaliações escritas (testes e provas). Ela desenvolve o conteúdo de Matemática em parceira com os alunos, de modo que eles evidenciem o que aprenderam por meio de vídeos criados por eles.

Em 2014, a professora desenvolveu um projeto-pesquisa em que utilizou como estratégia a produção de videoaulas para estudar Progressão Aritmética e Progressão Geométrica, em parceira com o Núcleo de Tecnologia Educacional (NTE16²) e o Grupo de Estudos em Educação Matemática (GEEM). O projeto envolveu 102 alunos de $2^{0}$ ano do Ensino Médio, divididos em quatro turmas (A, B, C e D), do turno vespertino do Colégio Polivalente de Vitória da Conquista - Bahia.

O projeto, que teve como tema Progressão Aritmética (PA) e Progressão Geométrica (PG), envolveu os alunos com atividades de pesquisa, estudo, elaboração e resolução de listas de exercícios, roteirização, produção de vídeo, participação em oficinas de produção e edição

\footnotetext{
${ }^{2}$ O Núcleo de Tecnologia Educacional de Vitória da Conquista (NTE16) foi extinto em janeiro de 2015. Fazia parte de uma rede de experimentação em informática educativa e tecnologias audiovisuais, que visavam formar professores no desenvolvimento de programas e projetos que incluíam as tecnologias digitais na escola. Na Bahia, existiam 16 núcleos; três localizados na capital, e 13, no interior com infraestrutura de informática e comunicação e uma equipe de educadores e especialistas que discutiam, incentivam, elaboraram e acompanhavam ações com o uso das tecnologias no contexto educacional. Os núcleos ofereciam oficinas, cursos presenciais e a distância dando suporte técnico-pedagógico, acompanhando e avaliando os projetos pedagógicos das unidades escolares relacionadas com a área geográfica de atuação. O NTE16 atendia 30 municípios entre Itapetinga e Vitória da Conquista.
}

ISSN 2526-2882 
de vídeos e apresentação para a classe do trabalho produzido. Possibilitou aos alunos serem autores, e não receptores, de informações, além de se sentirem valorizados e incluídos na ação.

\section{Fases de Desenvolvimento}

Na primeira fase, foi realizada a distribuição dos alunos por turma. Na turma D, por haver uma quantidade menor de alunos, ficaram quatro grupos. Foram sorteados três tópicos relacionados a PA e PG, de acordo com o Quadro 1.

Definidos os temas, os alunos foram orientados para a realização da pesquisa em livros e na Internet (sites e blogs matemáticos) sugeridos pela professora.

Na segunda fase, os alunos esclareceram as dúvidas com a professora, para que pudessem elaborar e responder a uma lista de exercícios com três questões (uma de cada tópico do conteúdo). As listas foram entregues à professora que as corrigiu e as devolveu aos alunos para que efetuassem os ajustes necessários para posterior apresentação aos colegas de classe.

Na terceira fase, aconteceu a realização da Oficina de Produção e Edição de Vídeo, quando os alunos tomaram conhecimento das etapas de criação de um vídeo: pré-produção, produção e pós-produção e o detalhamento e importância de cada uma dessas etapas. Após a oficina, foi solicitada a elaboração do roteiro do vídeo ou, em outras palavras, o vídeo escrito.

Quadro 1: Distribuição de grupos para a produção de vídeoaulas

\begin{tabular}{|c|l|}
\hline GRUPO & \multicolumn{1}{|c|}{ TÓPICO } \\
\hline $\mathbf{0 1}$ & $\begin{array}{l}\text { Sucessão ou Sequência Numérica (definição, classificação e } \\
\text { aplicação). Progressão Aritmética (PA) - (Um pouco de história, } \\
\text { introdução, definição e exemplos). Fórmula do Termo Geral de } \\
\text { uma PA. }\end{array}$ \\
\hline $\mathbf{0 2}$ & $\begin{array}{l}\text { Aplicações da Fórmula do Termo Geral de uma PA. Notação } \\
\text { especial de uma PA. Interpolação Aritmética. }\end{array}$ \\
\hline $\mathbf{0 3}$ & $\begin{array}{l}\text { Soma dos Termos de uma PA (Fórmula e aplicação). PA e Função } \\
\text { Afim, PA e Função Quadrática. }\end{array}$ \\
\hline \multirow{0}{*}{ o5 } & $\begin{array}{l}\text { Progressão Geométrica (PG) - (definição, classificação e } \\
\text { exemplos). Fórmula do Termo Geral de uma PG. Resolvendo } \\
\text { Problemas de PG. }\end{array}$ \\
\hline
\end{tabular}

Fonte: Elaboração de Cosmerina Angélica Soares Cruz Santana e Adriana Santos Sousa 
Os roteiros foram entregues à professora e devolvidos aos grupos com as correções necessárias para a execução das gravações das imagens. Os alunos foram liberados nos horários destinados às aulas de Matemática para a coleta de imagens e sons, produção de slides e organização do que foi determinado pelo roteiro.

Depois de gravadas, as imagens foram organizadas seguindo o roteiro preestabelecido, utilizando um programa de imagens, a exemplo, Windows Movie Maker, por ser o mais acessível entre os alunos e que, mesmo sendo um software proprietário, oferece download gratuito3.

A data da entrega das videoaulas foi determinada para uma semana após a edição dos vídeos. Cada grupo realizou a apresentação em sala de acordo com a ordem do conteúdo. Os alunos entregaram aos demais grupos uma cópia da lista elaborada, para que respondessem e entregassem à professora para correção. No momento da resolução dos exercícios, o grupo apresentador manteve-se disponível para auxiliar os colegas no esclarecimento das possíveis dúvidas.

Todos os alunos deveriam, obrigatoriamente, estar presentes em todas as apresentações das equipes, fazendo anotações nos cadernos, já que a participação era parte da avaliação. Ao final da aula, todos os alunos dos grupos assistentes deveriam preencher ficha de avaliação do grupo apresentador, levando em consideração critérios, como: fidelidade ao tema, didática, recursos utilizados, criatividade e segurança no momento da apresentação do conteúdo. A professora também avaliou os vídeos, analisando pontualidade, assiduidade, qualidade na produção e edição do vídeo, uso do tempo adequado, organização e planejamento, fidelidade ao tema, criatividade, objetividade e conhecimento do conteúdo.

A nota dos alunos na terceira unidade 4 compreendeu os seguintes aspectos: pesquisa (1 ponto), elaboração e resolução da lista (1 ponto), resolução das listas dos demais grupos (2 pontos), roteiro e apresentação da videoaula (4 pontos) e participação nas apresentações dos colegas ( 2 pontos) - totalizando 10 pontos.

As apresentações aconteceram até 31 de outubro de 2014. Para valorizar o trabalho, em reunião do GEEM, foi sugerido à professora um concurso dos vídeos com premiação dos melhores numa cerimônia comemorativa do grupo, como forma de incentivar e valorizar a criatividade e os esforços dos alunos.

3 Download gratuito no endereço http://windows.microsoft.com/pt-br/windows-live/moviemaker\#t1=overview.

$4 \mathrm{O}$ ano letivo das escolas públicas baianas é dividido em quatro unidades. Em cada unidade, o estudante pode alcançar nota 10,0 (dez). O aluno é aprovado para o ano subsequente quando alcança 20,0 (vinte) na soma das quatro unidades. 


\section{Alguns indícios das análises...}

Os Parâmetros Curriculares Nacionais (PCN) do Ensino Médio ensina que integrar as tecnologias à educação é importante para que aconteça "o desenvolvimento das capacidades de comunicação, de resolver problemas, de tomar decisões, de fazer inferências, de criar, de aperfeiçoar conhecimentos e valores, de trabalhar cooperativamente" (BRASIL, 1999, p.40).

Incorporar as tecnologias às atividades escolares não é tarefa fácil, pois são muitos e diversos os problemas encontrados pelos professores. Há aqueles que se referem à infraestrutura, como inexistência de estrutura adequada para o uso das tecnologias; inexistência de ambiente adequado para gravação das imagens, entre outros. E há aqueles referentes às questões pedagógicas, como dificuldades na elaboração do roteiro; problemas técnicos na edição (falta de habilidade no uso do editor de vídeos); dificuldades para organizar correta e sistematicamente o conteúdo pesquisado; falta de pontualidade dos alunos na entrega das atividades propostas.

Quando algo novo é proposto, para o professor, mesmo com todo planejamento e expectativas, alguns ajustes são necessários durante o processo de desenvolvimento do trabalho. Para os alunos, o novo também se mostra desafiador como menciona o Grupo $3 \mathrm{C}^{5}$ (2014): "a partir do momento que ficamos sabendo do projeto, ficamos apreensivos" e ainda: "não foi fácil organizar as ideias, pois o assunto proposto tinha uma dificuldade considerável". Mesmo com apreensão, o Grupo 2A (2014) valoriza ações como esta, quando diz:

Na escola [...] é muito difícil a valorização de projetos audiovisual ou teatral, aqui o ambiente escolar não oferece recursos para que projetos como este aconteçam. Mas, com esforços dos nossos professores, encontramos pequenas oportunidades que nos dá conhecimento e nos faz reconhecer o quanto o trabalho em equipe é importante.

Superados os empecilhos, a construção de situações problemas envolvendo PA e PG na linguagem multimodal permitiu que os alunos pudessem ser agentes ativos no processo de aprendizagem, produzindo de forma criativa, eficaz e colaborativa o próprio conhecimento. Segundo Moran (2008, p. 23),

aprendemos melhor, quando vivenciamos, experimentamos, sentimos, descobrindo novos significados, antes despercebidos. Aprendemos mais, quando estabelecemos pontes entre a reflexão e a ação, entre a experiência e a conceituação, entre a teoria e a prática: quando uma completa a outra.

\footnotetext{
5 Os grupos foram identificados pelo tópico do conteúdo em que desenvolveram a pesquisa, seguido da letra que identifica a turma. Exemplo: Grupo 1D (1- Sucessão ou Sequência Numérica (definição, classificação e aplicação), Progressão Aritmética (PA) - (Um pouco de história, introdução, definição e exemplos), Fórmula do Termo Geral de uma PA e turma $2^{\circ}$ Ano D).
} 
A articulação entre teoria e prática foi vivenciada no desenrolar da pesquisa: na seleção cautelosa das fontes de informação, análise e sintetização das ideias principais, na criação, captura e seleção das imagens, na relação entre a informação dos textos e as imagens, enfim, na compreensão dos conteúdos matemáticos e na formatação da linguagem audiovisual. Todo esse processo teve com a orientação contínua da professora.

No processo de construção do conhecimento e apresentação dos resultados, os alunos buscaram incorporar metodologias diferenciadas na forma de exibir o vídeo e nas atividades para atender às expectativas dos colegas e da professora no desenvolvimento dos eixos cognitivos, habilidades e competências matemáticas elencados nos PCN.

A publicação das videoaulas na Internet, inicialmente, provocou resistência nos alunos, pois ficaram temerosos com a exposição na grande rede. No entanto, percebendo a importância do trabalho narraram com alegria e emoção o compartilhamento: "ficamos orgulhosos ao ver nossa videoaula ser apresentada, pois percebemos que temos capacidade de desenvolver trabalhos assim, não só em sala de aula, mas também fazendo com que através das redes sociais pode haver pessoas que poderão aprender, assim como nós" (GRUPO $3 \mathrm{C}$, 2014).

No que diz respeito à avaliação do trabalho, os alunos aprovaram a proposta da professora de criação dos vídeos durante a unidade, conforme relato do Grupo 5A (2014): “o método da videoaula foi, sem dúvida, uma ótima forma de avaliação, pois, diferente das provas e testes, aprendemos de forma criativa e interessante". O Grupo $3 \mathrm{C}$ (2014) endossa dessa forma a aprovação do Grupo 5A:

Gostamos do método de avaliação utilizado porque o assunto foi abordado de uma forma mais descontraída e houve mais compreensão. [...] Houve bastante interação dos colegas, ficamos mais unidos e teve a colaboração de todos os componentes. Depois de muito esforço e estudo, conseguimos compreender o assunto.

Para a professora, mesmo em meio às dificuldades e ao cansaço, o resultado foi muito satisfatório, principalmente por ter identificado interesse e motivação dos alunos no desenvolvimento de própria aprendizagem.

Quando os alunos mostravam dificuldades na assimilação do conteúdo, a professora as identificava e fazia opção por outra forma de abordar o conteúdo.

Outro ponto positivo foi trabalhar em grupo e proporcionar o estreitamento nas relações aluno-aluno e professora-alunos, tornando o ambiente da sala de aula favorável ao aprendizado. 


\section{Referências}

BORBA, M.C.; PENTEADO, M.G. Informática e Educação Matemática. $3^{\text {a }}$ Ed., Belo Horizonte, MG: Autêntica, 2003 (Coleção Tendências em Educação Matemática).

BRASIL. Ministério da Educação. Secretaria de Educação Média e Tecnológica. Parâmetros Curriculares Nacionais: Ensino Médio. Brasília: MEC/SEMTEC, 1999.

DEMO, P. Os desafios da linguagem do século XXI para o aprendizado na escola. Palestra, Faculdade OPET, junho 2008. Site: http://www.nota10.com.br Acesso em 23/06/2015.

KENSKI, V. M., Educação e tecnologias: o novo ritmo da informação, $6^{\text {a }}$ Ed, Campinas, SP. Papirus, 2010. (Coleção Papirus Educação).

MERCADO, L.P.L. Práticas de formação de professores na Educação a Distância. Maceió: UFAL, 2008.

MORAN, J. M.. O vídeo na sala de aula. In: Comunicação \& Educação. São Paulo, ECA- Ed. Moderna, [2]: 27 a 35, jan./abr. de 1995.

MORAN, J. M.. Ensino e aprendizagem inovadores com tecnologias audiovisuais e telemáticas. In: MORAN, J. M.; MASETTO, M. T.; BEHRENS, M. A. Novas tecnologias e mediação pedagógica. Campinas, SP: Papirus, 2008.

MORAN, J. M. Contribuições para uma pedagogia da educação online. In Educação Online. Org. Marco Silva. $3^{\text {a }}$ Ed. São Paulo: Edições Loyola, 2011.

PRETTO, N.L. Uma escola com/sem futuro: educação e multimídia. Campinas, SP: Papirus, 1996.

ROCATO, Paulo Sérgio. As concepções dos professores sobre o uso de vídeos como potencializadores do processo de ensino e aprendizagem. 2009. Dissertação (Mestrado Profissional em Ensino de Ciências e Matemática) - Universidade Cruzeiro do Sul, UNICSUL, São Paulo (SP). Orientador: Carlos Fernando de Araújo Júnior.

SCUCUGLIA, R. On the nature of students' digital mathematical performances: When elementary school students produce mathematical multimodal artistic narratives. Alemanha: Verlag / LAP Lambert Academic Publishing, 2012.

SOUSA, A.S. Professores de Matemática e Recursos Didáticos Digitais: Contribuições de uma formação continuada online. 126f. Dissertação (Mestrado) - Programa de PósGraduação Mestrado em Educação Científica e Formação de Professores, Universidade Estadual do Sudoeste da Bahia, Jequié-BA, 2014. 


\section{Biografia Resumida}

Cosmerina Angélica Soares Cruz Santana. Licenciada em Ciências com Habilitação em Matemática (UESB - Vitória da Conquista), Especialista em Ciência da Computação (UESB - Vitória da Conquista), Professora do Colégio Polivalente de Vitória da Conquista.

Currículo Lattes: http://lattes.cnpq.br/4308428805354512

Contato: angelicasantana7@gmail.com

Adriana Santos Sousa. Licenciada em Ciências com Habilitação em Matemática (UESB - Vitória da Conquista), Mestra em Ensino de Ciências e Matemática (UESB- Jequié). Professora dos Colégios Estaduais Nilton Gonçalves e Vilas Boas Moreira (Vitória da Conquista).

Currículo Lattes: http://lattes.cnpq.br/8991829370462435

Contato: adrianassousa@gmail.com 